\title{
Produção do conhecimento sobre o ensino de geografia para pessoas com deficiência
}

\author{
Taís Buch Pastoriza ${ }^{1}$ \\ Rosimeire Maria Orlando ${ }^{2}$ \\ Katia Regina Moreno Caiado ${ }^{3}$
}

\section{Introdução}

O presente artigo tem como foco a produção do conhecimento sobre o ensino de geografia para pessoas com deficiência.

Certo é que o crescimento das matrículas de pessoas com deficiência nas escolas regulares tem se constituído, por um lado, como uma conquista histórica desses sujeitos, mas, por outro, como um desafio para os professores e a gestão escolar. E o desafio se coloca ao analisarmos as dificuldades da escola, principalmente a pública, em propiciar as condiçóes de aprendizagem dos conteúdos escolares para alunos de diferentes classes sociais.

1 UFSCar - Universidade Federal de São Carlos. Programa de Pós-Graduação em Educação. Sorocaba - São Paulo - Brasil. Mestranda. Bolsista Obeduc/Capes. taispastoriza@hotmail.com

2 UFSCar - Universidade Federal de São Carlos. Licenciatura em Educação Especial Programa de Pós-graduação em Educação Especial. São Carlos - São Paulo - Brasil. Coordenadora do Núcleo de Apoio à Pesquisa da UFSCar do projeto em rede "Acessibilidade no Ensino Superior"(Obeduc/Capes).meiremorlando@gmail.com

3 UFSCar - Universidade Federal de São Carlos. Curso de Pedagogia - Programa de Pós-graduação em Educação Especial. São Carlos - São Paulo. Programa de Pós-graduação em Educação. Sorocaba - São Paulo - Brasil. 
A política dita como inclusiva, na qual se propóe matricular pessoas com deficiência nas escolas regulares, termina por tornar-se mais um elemento complicador para a equipe escolar, com destaque para o professor cuja formação tem apresentado lacunas mesmo em sua área de ensino.

Diante destas colocaçóes, podemos problematizar: Como tem se dado a formação inicial dos professores? Que condiçôes de acessibilidade são destacadas? Como as pesquisas apontam a escolarização desses sujeitos? Qual o enfoque que tem se destacado?

As pesquisas na área da educação têm a função social de acumular conhecimentos que possam auxiliar a formação e a prática dos professores, por isso a importância do levantamento das produçóes acadêmicas.

Nesta direção, os objetivos do presente estudo de levantamento foram: identificar o panorama da produção de pesquisas na interface ensino de geografia e inclusão, identificar as universidades e os pesquisadores de referência, bem como classificar e quantificar os temas/enfoques abordados.

O levantamento de produçóes, como um estudo epistemológico, é importante devido à possibilidade de "discernir a história dos conhecimentos científicos que já foram superados, bem como a dos que permanecem atuais, colocando em marcha o processo científico" (SILVA; GAMBOA, 2011, p.377). Assim como identificar as tendências e as demandas atuais de pesquisa.

\section{Apresentação e análise dos dados}

De acordo com levantamento realizado no Banco de Teses e Dissertaçóes da Capes, no período de 1993 a 2012, os descritores utilizados foram: "geografia e inclusão" (371 títulos), "geografia e cegos" (22 títulos), "educação inclusiva e geografia” (18 títulos), "geografia e deficiência visual” (17 títulos) e "cartografia tátil” (10 títulos), totalizando 438 títulos.

De posse desses dados, eliminaram-se as produçôes com outros temas centrais e as duplicadas, após a leitura dos resumos e títulos dos trabalhos, e restaram 22 trabalhos que se encaixaram no escopo deste trabalho, conforme apresentamos no Gráfico 1 .

O primeiro trabalho data de 1993, porém, principalmente a partir de 2006, haverá um crescimento das produções.

Há três períodos importantes para a produção de dissertaçôes e teses na área: de 2000 a 2004, de 2007 a 2010 e a partir de 2011. Entre 2000 e 2004 se manteve um trabalho por ano.

Entre 2006 e 2010 a produção dobra para dois trabalhos por ano. Em 2011 são três e em 2012, seis trabalhos. 
Gráfico 1. Distribuição anual de trabalhos de 1993 a 2012

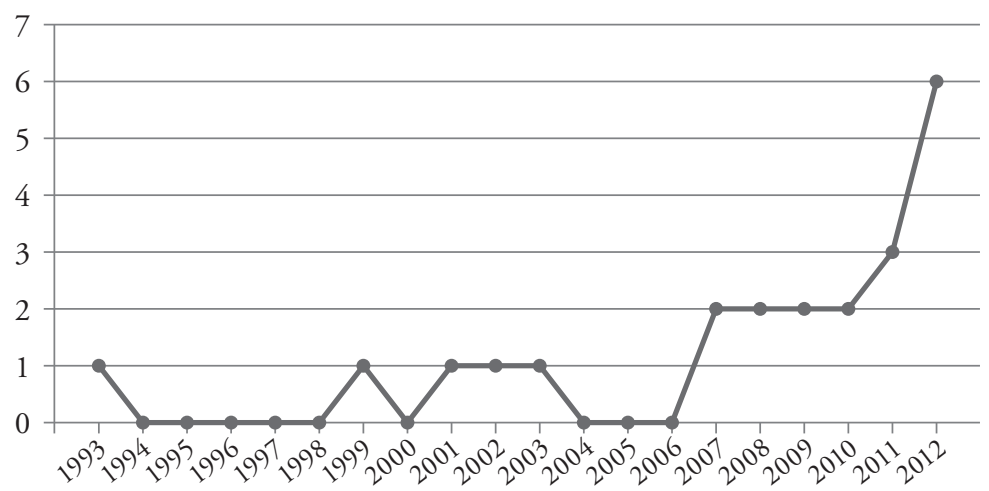

Fonte: Dados da pesquisa.

No primeiro período, pode-se considerar a influência da Política Nacional para Integração da Pessoa Portadora de Deficiência (PNIPPD), decreto n. 3.298/99, que pode ter incentivado as poucas produçóes até 2004.

O segundo momento, de 2006 a 2010, é marcado pela implantação do "Programa Educação Inclusiva: direito à diversidade” pelo MEC/Seesp desde 2003. Garcia e Michels (2001) afirma que esse é "um dos Programas mais importantes da atual política de Educação Especial” sendo implementado nas redes de ensino estaduais e municipais.

Nesse sentido, é possível que o Programa, juntamente com os recursos destinados a esse fim, tenha mobilizado projetos de extensão nos quais as universidades formam parcerias com as escolas estaduais, como a realizada por Ventorini $(2007,2012)$.

Por de se tratar de uma política do Estado de São Paulo, veremos que a maior parte da produçáo está concentrada nesse Estado, principalmente ao abordar a deficiência visual.

Outra política importante, nesse período, surge após o texto da Convenção Internacional dos Direitos das Pessoas com Deficiência, com a aprovação e publicação do Decreto n. 6.949, em 2009.

Com importante repercussão, segundo Caiado, Berribille e Saraiva (2013, p.20), o Decreto no 6.949 trata a educação "enquanto um direito da pessoa com deficiência que deve se dar sem discriminação, ou seja, com igualdades de oportunidades, em todos os níveis de educaçáo, com o aprendizado assegurado ao longo de toda a vida".

Ainda problematizando, como considerar essa igualdade de oportunidades? A que aprendizado o decreto se refere? Para que o acesso ao conhecimento de fato ocorra sabemos que é necessário formar profissionais, produzir conhecimento sobre o ensino e aprendizagem na área e produzir materiais adaptados em cada 
disciplina escolar. Ou seja, criar condições de acessibilidade que perpassem desde a formação dos professores até a devida apropriação dos conteúdos escolares.

Em âmbito nacional, há um impacto tanto das políticas como das matrículas crescentes dos alunos com deficiência nas escolas regulares apontada por Meletti e Bueno (2010), que pode ter influenciado o terceiro momento, a partir de 2011, com a dispersáo das publicaçóes por universidades federais em outros estados como Minas Gerais (Universidade Federal de Uberlândia), Santa Catarina (UFSC), Rio Grande do Sul (UFRGS), Universidade Federal do Pará (UFPA), Universidade Federal do Maranhão (UFMA) e Universidade Estadual de Londrina (UEL), como se verifica na Tabela 1.

Tabela 1. Distribuição anual por instituição de ensino superior (1999-2012)

\begin{tabular}{|c|c|c|c|c|c|c|c|c|c|c|c|c|c|c|c|}
\hline IES/Ano & 99 & 00 & 01 & 02 & 03 & 04 & 05 & 06 & 07 & 08 & 09 & 10 & 11 & 12 & Total \\
\hline USP & & & & 1 & & & & & & & 1 & 1 & 1 & & 5 \\
\hline UFRGS & & & 1 & & 1 & & & & & & & & 1 & & 3 \\
\hline UFU & & & & & & & & & & & & & 1 & 2 & 3 \\
\hline UFMA & & & & & & & & & & & & & 1 & 1 \\
\hline UFPA & & & & & & & & 1 & & & & & 1 & 2 \\
\hline UEL & & & & & & & & & & & & & & 1 & 1 \\
\hline UFRN & & & & & & & & & 1 & & & & & 1 \\
\hline PUC & & & & & & & & & & & 1 & & & & 1 \\
\hline UFSC & & & & & & & & & & 1 & & 1 & & & 2 \\
\hline UNESP & & & & & & & & 1 & & & & & 1 & 2 \\
\hline UFMG & 1 & & & & & & & & & & & & & & 1 \\
\hline Total & 1 & & 1 & 1 & 1 & & & & 2 & 2 & 1 & 1 & 2 & 6 & 21 \\
\hline
\end{tabular}

Fonte: Dados da pesquisa.

$\mathrm{Na}$ Tabela 1 optamos por não mostrar a primeira publicação de 1993 da Universidade de São Paulo, pelo fato de já haver citado como pioneira.

A metodologia utilizada para o levantamento das produçóes é pautada nos estudos de Bueno (2010), nos quais a análise parte de determinados aspectos das produçóes como: onde e quando foram produzidas, sobre o que e de que forma incidem as narrativas. (BUENO, 2010, p.2)

Ao levantarmos as Instituiçóes de Ensino Superior (IES) de origem dos trabalhos, verifica-se a concentração das universidades públicas das regiōes Sudeste e Sul. São quatro as exceçôes: a PUC-São Paulo, por ser particular, a UFPA, da regiâo Norte, a Universidade Federal do Rio Grande do Norte (UFRN) e a UFMA, ambas na região Nordeste. 
Tabela 2. Instituição em que as dissertações e teses foram defendidas (1993-2012)

\begin{tabular}{|c|c|c|}
\hline IES & Quantidade & $\%$ \\
\hline USP & 5 & $22,7 \%$ \\
\hline UFU & 3 & $13,6 \%$ \\
\hline UFRGS & 3 & $13,6 \%$ \\
\hline UFPA & 2 & $9 \%$ \\
\hline UFSC & 2 & $9 \%$ \\
\hline UNESP & 2 & $9 \%$ \\
\hline PUC & 1 & $4,5 \%$ \\
\hline UEL & 1 & $4,5 \%$ \\
\hline UFRN & 1 & $4,5 \%$ \\
\hline UFMG & 1 & $4,5 \%$ \\
\hline UFMA & 1 & $4,5 \%$ \\
\hline Total & 22 & $100 \%$ \\
\hline
\end{tabular}

Fonte: Dados da pesquisa.

Tabela 3. Tema central das produçóes na interface da Educação Especial

\begin{tabular}{|l|c|c|}
\hline \multicolumn{1}{|c|}{ Tema } & Quant. & $\%$ \\
\hline $\begin{array}{l}\text { Práticas de ensino de geografia para alunos } \\
\text { com deficiência visual }\end{array}$ & 9 & $41 \%$ \\
\hline $\begin{array}{l}\text { Práticas de ensino de geografia } \\
\text { para alunos com cegueira }\end{array}$ & 4 & $18 \%$ \\
\hline $\begin{array}{l}\text { Formação inicial de professores de geografia } \\
\text { na perspectiva da inclusão escolar }\end{array}$ & 3 & $13,6 \%$ \\
\hline $\begin{array}{l}\text { Práticas de ensino de geografia para alunos } \\
\text { com surdez }\end{array}$ & 3 & $13,6 \%$ \\
\hline $\begin{array}{l}\text { Práticas de ensino de geografia para alunos } \\
\text { com deficiência em geral }\end{array}$ & 1 & $4,5 \%$ \\
\hline $\begin{array}{l}\text { Formação continuada de professores de } \\
\text { geografia na perspectiva da inclusão escolar }\end{array}$ & 1 & $4,5 \%$ \\
\hline $\begin{array}{l}\text { Práticas de ensino de geografia para alunos } \\
\text { com síndrome de Down }\end{array}$ & 1 & $4,5 \%$ \\
\hline Total & 22 & $100 \%$ \\
\hline
\end{tabular}

Fonte: Dados da pesquisa. 
Se considerada a instituição, há uma dispersão das produções. Entretanto, a instituição que mais concentra a produção é a Universidade de São Paulo (USP), sob orientação da professora dra. Regina Araújo de Almeida, a primeira a defender uma tese na área de ensino de geografia para alunos com deficiência visual.

Em relação aos temas, o mais frequente é o do ensino de geografia para pessoas com deficiência visual (baixa visão e/ou cegueira). Entretanto, os dados apontam para a diversificação dos temas nas diferentes deficiências a partir de 2011 (Tabela 3).

Os três trabalhos levantados sobre surdez são de 2012, sendo dois produzidos na Universidade Federal de Uberlândia (UFU) e um na Universidade Federal de Londrina (UEL).

O único trabalho sobre o ensino de geografia para alunos com síndrome de Down data de 2011 e foi produzido na UFRGS.

Com um número diminuto de trabalhos, mas tema de grande importância, forma encontrados três trabalhos sobre a formação na educação superior de professores de geografia para a inclusão de pessoas com deficiência no geral, sendo um de 2007 e dois de 2012. Destes, dois foram produzidos na UFPA: um de 2007 e outro de 2012. O outro trabalho foi defendido na UFMA.

A partir dos dados e da análise com base na legislaçáo, buscamos traçar um panorama da produçáo geral sobre pessoas com deficiência, tendo por objetivo aprofundar a análise das pesquisas sobre ensino de geografia para pessoas com deficiência visual (baixa visão e cegueira), tema ainda em destaque entre as produçôes de ensino de geografia na interface da educação especial.

\section{A pesquisa sobre o ensino de geografia para alunos com deficiência visual (baixa visão e cegueira)}

As pesquisas com esse enfoque são majoritariamente elaboradas por instituições no Estado de São Paulo, totalizando 53\% entre públicas (estaduais) e uma privada (Gráfico 2).

Sobre as orientaçóes das quinze produçóes, cinco se deram por diferentes orientadores, ou seja, um terço foi feito por pesquisadores que não orientaram outros trabalhos sobre o assunto posteriormente.

Há apenas uma pesquisadora que orientou mais de dois trabalhos sobre o assunto. Conclui-se que há uma dispersão de orientaçóes, fato que pode comprometer o acúmulo de conhecimentos, resultados e a criação de linhas de pesquisa consolidadas. 
Taís Buch Pastoriza, Rosimeire Maria Orlando e Katia Regina Moreno Caiado

Gráfico 2. Porcentagem das produçôes em diferentes IES

\begin{tabular}{lll}
\hline USP & (São Paulo) & $33 \%$ \\
\hline \hline UNESP & (Rio Claro) & $13 \%$ \\
\hline \hline UFSC & (Florianópolis) & $13 \%$ \\
\hline \hline UFRGS & (Porto Alegre) & $13 \%$ \\
\hline \hline PUC & (São Paulo) & $7 \%$ \\
\hline \hline UFMG & (Belo Horizonte) & $7 \%$ \\
\hline \hline UFRN & (Natal) & $7 \%$ \\
\hline \hline UFU & (Uberlândia) & $7 \%$ \\
\hline
\end{tabular}

Fonte: Dados da pesquisa.

Gráfico 3. Matrículas de pessoas com cegueira na educação básica na modalidade de ensino regular

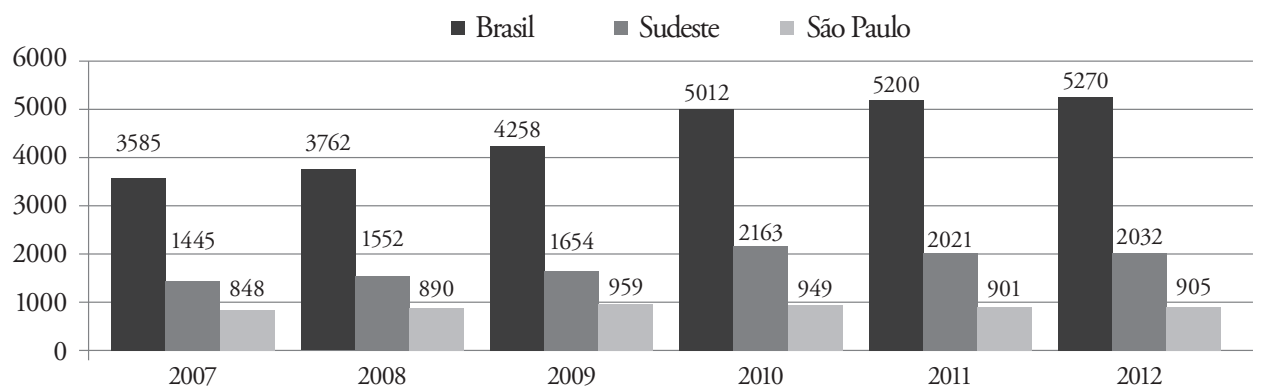

Fonte: Censo Escolar 2012. Organização das autoras. 
Tabela 4. Distribuição das produçóes por orientador

\begin{tabular}{|c|c|c|}
\hline Orientação & $\begin{array}{c}\text { Quantidade de } \\
\text { trabalhos }\end{array}$ & $\%$ \\
\hline Uma orientação & 7 & $32 \%$ \\
\hline $\begin{array}{c}\text { Mais de uma } \\
\text { orientação }\end{array}$ & 15 & $68 \%$ \\
\hline Total & 22 & $100 \%$ \\
\hline
\end{tabular}

Fonte: Dados da pesquisa.

Em relação ao programa em que as teses e dissertações foram defendidas, há uma predominância da Geografia, com 87\% dos trabalhos defendidos na área.

Tabela 5. Programa em que as produçóes foram defendidas (1993-2012)

\begin{tabular}{|c|c|c|}
\hline Programa & Quantidade & \% \\
\hline Geografia & 13 & $87 \%$ \\
\hline Educação & 2 & $13 \%$ \\
\hline Total & 15 & $100 \%$ \\
\hline
\end{tabular}

Fonte: Dados da pesquisa.

No que diz respeito aos programas de pós-graduação, a maioria é de mestrado, conforme apontamos na Tabela 6 . A explicação para o resultado em parte se relaciona com a quantidade de vagas de mestrado que é maior do que a de doutorado, e o tempo destinado à sua finalização.

Tabela 6. Distribuição por nível de titulação (1993-2012)

\begin{tabular}{|c|c|c|}
\hline Nível & Quantidade & \% \\
\hline Mestrado & 12 & $80 \%$ \\
\hline Doutorado & 3 & $20 \%$ \\
\hline Total & 15 & $100 \%$ \\
\hline
\end{tabular}

Fonte: Dados da pesquisa.

Sobre os temas, a corrente teórica sobre cartografia tátil e multissensorial é destaque na maioria dos trabalhos (60\%), já que além da USP, a Universidade Federal de Santa Catarina (UFSC) também trabalha nessa perspectiva com o Laboratório de Cartografia Tátil e Escolar (Labtate).

Em contrapartida, há apenas um trabalho sobre trajetória escolar e o ensino de geografia, um acompanhamento dos atendimentos especializados, das vivências de um cego ao longo da vida e na escola regular. 
Tabela 7. Tema central das produçóes de ensino de geografia para pessoas com deficiência visual

\begin{tabular}{|l|c|}
\hline \multicolumn{1}{|c|}{ Tema } & Quantidade \\
\hline $\begin{array}{l}\text { Cartografia tátil/multissensorial: formação de professores e } \\
\text { ensino para pessoas com deficiência visual }\end{array}$ & 9 \\
\hline $\begin{array}{l}\text { Desafios atuais do ensino de geografia para pessoas com defi- } \\
\text { ciência visual na perspectiva inclusiva }\end{array}$ & 2 \\
\hline $\begin{array}{l}\text { Formaçáo do professor (geografia) para o ensino de jovens e } \\
\text { adultos com deficiência visual }\end{array}$ & 1 \\
\hline $\begin{array}{l}\text { Trajetória escolar de uma pessoa cega na aprendizagem de } \\
\text { imagens adaptadas }\end{array}$ & 15 \\
\hline Total & 2 \\
\hline
\end{tabular}

Fonte: Dados da pesquisa.

Conforme apontado na Tabela 7 , os dados parecem indicar mais para um enfoque nos recursos e/ou materiais didáticos adaptados, em vez de uma investigação pautada nos desafios do ensino e aprendizagem de geografia e na trajetória escolar desses alunos.

Considerando que as pesquisas na interface educação especial e ensino de geografia são praticamente escassas e, consequentemente, o acúmulo de conhecimentos na área específica ainda é inicial, algumas considerações e hipóteses podem ser tecidas.

$\mathrm{O}$ enfoque parece estar invertido: primeiro se prioriza as pesquisas que tratam da adaptação para minoritariamente tentar compreender a trajetória do aluno em relação aos conhecimentos geográficos, a formação e as práticas dos professores, assim como seus desafios, entre outros aspectos fundamentais que antecedem as alteraçóes curriculares, como por exemplo, a formação na educação superior.

Isso fica claro quando Heredero (2007) nos aponta que as alteraçóes curriculares para pessoas com deficiência não devem se limitar aos ajustes de pequeno porte que, se por um lado, pode facilitar o processo de ensino e aprendizagem nas salas de atendimento especializado para um grupo de pessoas com a mesma deficiência, por outro, promove uma individualização extrema do ensino.

Se exemplos de adaptaçóes de pequeno porte são adequar, priorizar e introduzir os objetivos, conteúdos e critérios de avaliação, alterar periodicamente os objetivos ou critérios de avaliação e todas as alterações necessárias na metodologia (HEREDERO, 2007, p.5), cabe questionarmos: somente as adaptaçóes de pequeno porte são suficientes? O que garantem?

Certo é que os indivíduos com deficiência requerem adaptaçóes individuais. Entretanto, centralizar o foco nas especificidades dos alunos mais do que em 
adaptaçóes mais significativas, como a formação dos professores, a organização das salas e da escola para atendimento, a relação entre professor e aluno e entre a família e a escola, dentre outras, podem induzir os pesquisadores na área a acreditarem que mudanças apenas na metodologia já são suficientes para incluir de fato a pessoa com deficiência.

Nesta direção, Góes (2004, p.74) afirma que somente as adaptaçóes não bastam: "são indispensáveis projetos diferenciados e não apenas pequenos ajustes". Já que sem alterar o delineamento do currículo e as metodologias, sem estabelecer esquemas de suporte efetivo ao professor, a escola não responde ao compromisso com o desenvolvimento e a aprendizagem dos indivíduos diferentes (GÓES, 2004, p.74), nem às reais condiçóes de acessibilidade ao conteúdo escolar.

É importante destacar práticas docentes problemáticas cotidianas que são recorrentes com as pessoas com deficiência e que influenciam na aprendizagem. Góes (2008) verifica que a imagem do aluno especial na escola é de "semilocutor", na qual se impóe os limites de suas possibilidades de construçáo de sentido que deslegitima a fala do sujeito com deficiência.

Essas indicaçóes mostram uma realidade em que se restringem as oportunidades para o desenvolvimento da linguagem e do pensamento, e ao aluno especial continua sendo-lhe creditadas mais suas dificuldades que suas possibilidades (GÓES, 2008, p.41).

É preciso repensar a concepção de deficiência de modo ela se deslocar do ponto de vista biológico e orgânico para a visão social na qual a superação se dá pela interaçáo social na escola, entre os alunos, durante as aulas, em uma perspectiva interativa de ensino e aprendizagem (FERREIRA, M. C. C.; FERREIRA, J. R. 2004).

Os professores relatam ter dificuldades para lidar com a proposta de inclusão atual, quando não muita dificuldade, devido em parte à falta de formação (GÓES, 2004; CHAVES, 2010; ALMEIDA, 2011; OLIVEIRA; 2008).

Não tem havido um preparo prévio dos professores da sala regular para o exercício pedagógico com o aluno com deficiência, o "próprio exercício das relaçôes de ensino tem preparado as professoras para receber e acolher a 'alteridade deficiente"' (FONTANA; FURGERI; PASSOS, 2004, p.163).

Ou seja, os professores têm aprendido "na prática", com todas as dificuldades para o professor e comprometimentos de aprendizagem que isso pode acarretar para a pessoa com deficiência.

Em síntese, a bibliografia na área tem apontado para duas temáticas: as metodologias de ensino, sendo a cartografia tátil e/ou multissensorial predominante, e a formação e/ou práticas pedagógicas dos professores de geografia em relação ao ensino para as pessoas com deficiência.

Sobre a formação dos professores, o foco tem sido nos desafios da prática docente em ensinar a pessoa com deficiência na sala comum sem ter tido for- 
mação, inicial ou continuada, na área. São escassas as propostas de formação de professores de geografia que contemplem as pessoas com deficiência para além das adaptaçóes metodológicas de ensino.

A partir desta problematização, é possível verificar que as ações políticas quando adentram os portóes escolares realmente parecem impactar a formação dos professores, geralmente não formados para atuar com salas de aulas heterogêneas e socializadas em ambientes em que tais crianças eram segregadas em instituições, classes especiais ou na própria residência, delegadas a professores especialistas e pouco afeitas ao ensino e aprendizagem de conteúdos escolares (BUENO, 1999).

Sabe-se da importância da formação do professor, de modo geral, ou aqui em específico, de geografia para ensinar os conteúdos da disciplina para os alunos com baixa-visão e/ou cegueira. Entretanto, qual formação seria essa? Qual perspectiva teórica e metodológica seria adequada? Sobre qual concepção de deficiência?

Apesar do avanço da área nos últimos anos, muitos são os questionamentos que ainda precisam ser pesquisados e debatidos para instrumentalizar os professores e suas práticas para a realidade que se apresenta: a crescente escolarização desses sujeitos e seu direito à aprendizagem.

\section{Considerações finais}

Nos levantamentos de produções na interface ensino de geografia e educação especial/deficiência visual, buscamos identificar as Instituições de Ensino Superior nas quais as teses e dissertaçóes são elaboradas, assim como os temas e focos de pesquisa.

A maioria das produçóes está concentrada na regiấo Sudeste e no Estado de São Paulo, cuja deficiência mais abordada é a visual na temática da cartografia tátil.

Nos últimos anos, parece haver uma tendência de diversificação dos temas de pesquisa, já que até 2011 havia uma concentração de produçôes na área da deficiência visual, e a partir desse período houve um aumento significativo de trabalhos sobre ensino de geografia e educação especial, porém com outras deficiências/temas.

A predominância da cartografia tátil, como uma proposta sistematizada de adaptação de materiais didáticos táteis e/ou multissensoriais, nas pesquisas indica que, por um lado, há uma consolidação das técnicas de produção de mapas adaptados para pessoas com deficiência visual no Brasil, assim como sua eficácia para a sua aplicação nas escolas e instituiçôes de atendimento educacional especializado. Por outro, no âmbito do acesso aos conteúdos curriculares por sujeitos com deficiência visual, as pesquisas precisam avançar para além das adaptaçóes metodológicas para contemplar várias dimensóes da aprendizagem e o contexto da escola pública brasileira atual. 
Entre as questóes pouco pesquisadas e que se apresentam como campos de pesquisa importantes e necessários na interface são: o ensino e aprendizagem de conteúdos escolares de geografia nas trajetórias escolares de pessoas com deficiência e a importância da interação social na aprendizagem dos alunos com deficiência.

Muitos são os trabalhos que citam a formação do professor de geografia para ensinar pessoas com deficiência. Entretanto, são escassas as indicações sobre conteúdos, referenciais teóricos e metodológicos, entre outros aspectos que permeiam essa formação.

Sobre as pesquisas no âmbito de todas as deficiências, não só a visual, até 2012, ano de realização do levantamento, não identificamos nenhuma na interface do autismo, deficiência múltipla ou deficiência intelectual.

Nesse sentido, é preciso que mais pesquisas sejam elaboradas na escola comum que abordem o ensino de geografia para as pessoas com deficiências pouco ou ainda não pesquisadas, a relação professor-aluno e a interação social entre os alunos e a formação do professor de forma mais propositiva. ${ }^{4}$

\section{Referências}

ALMEIDA, D. C. S. Entre a escola e a sociedade: bases para a formaçáo continuada de professores de Geografia na perspectiva da inclusão escolar de estudantes com baixa visão e cegos, em Uberlândia-MG. Dissertação (Mestrado em Geografia). Universidade Federal de Uberlândia. Uberlândia-MG. 2011.

BUENO, J. G. S. Crianças com necessidades educativas especiais, política educacional e a formação de professores: generalista ou especialista. Revista Brasileira de Educação Especial, n.5, Piracicaba, Unimep, 1999.

BUENO, J. G. Deficiência e Ensino Superior: balanço das dissertações e teses brasileiras (1987-2006). In: VICTOR, S. L.; CHICON, J. F. Educação Inclusiva de crianças, adolescentes, jovens e adultos. Vitória: Edufes, 2010. p.255-272.

CAIADO, K. R. M. (Org.). Trajetórias escolares de alunos com deficiência. São Carlos: Edufscar, 2013a. 242p.

CAIADO, K. R. M.; BERRIBILLE, G. R.; SARAIVA, L. A. Educação e deficiência na voz de quem viveu essa trama. In: CAIADO, K. R. M. (Org.). Trajetórias escolares de alunos com deficiência. São Carlos: Edufscar, 2013b. 242p.

CHAVES, A. P. N. Ensino de Geografia e a cegueira: diagnóstico da inclusão escolar na Grande Florianópolis. Dissertação (Mestrado em Geografia). Universidade Federal de Santa Catarina. Florianópolis-SC. 2010.

4 Agradecemos à Capes, agência financiadora da pesquisa que pertence ao Programa Observatório da Educação (Obeduc). 
FERREIRA, M. C. C.; FERREIRA, J. R. Sobre inclusão, políticas públicas e práticas pedagógicas. In: GÓES, M. C. R.; LAPLANE, A. L. F. Políticas e práticas de educação inclusiva. Campinas: Autores Associados, 2004. p. 21- 48.

FONTANA, R. A. C.; FURGERI, D. K. P.; PASSOS, L. V. L. Cenas cotidianas de inclusão: sentidos em jogo. In: GÓES, M. C. R.; LAPLANE, A. L. F. Políticas e práticas de educação inclusiva. Campinas: Autores Associados, 2004. p.149-165.

GARCIA, R. M. C.; MICHELS, M. H. A política de educação especial no Brasil (19912011): análise da produção do GT15-Educação Especial da Anped. Revista Brasileira de Educação Especial, Marília, v.17, p.105-124, 2011.

GÓES, M. C. R. Desafios da inclusão de alunos especiais: a escolarização do aprendiz e sua constituição como pessoa. In: GÓES, M. C. R.; LAPLANE, A. L. F. Políticas e práticas de educação inclusiva. Campinas: Autores Associados, 2004. p.69-92.

GÓES, M. C. R. Contribuiçôes da abordagem histórico-cultural para a pesquisa em Educação Especial. In: BATISTẢ, J. C.; CAIADO, K. R. M.; JESUS, D. M. (Orgs.). Educação Especial: diálogo e pluralidade. v.1. Porto Alegre: Mediaçâo, 2008. p.37-46.

HEREDERO, E. S. Las adaptaciones curriculares de pequeno porte o no significativas en el contexto brasileño. Revista Ibero-Americana de Estudos em Educação, v.2, n. 2, 2007.

MELETTI, S. M. F.; BUENO, J. G. S. Escolarização de alunos com deficiência: uma análise dos indicadores sociais no Brasil (1997-2006). In: Reunião Anual da Anped, 33, 2010, Caxambu. Anais... 2010.

OLIVEIRA, A. A. S.; LEITE, L. P. Escola inclusiva e as necessidades educacionais especiais. In: MANZINI, E. J. (Org.) Educação Especial: temas atuais. Marília: Unesp, 2000.

OLIVEIRA, R. V. Itinerário educacional de uma aluna cega e a busca pela imagem adaptada. Dissertação (Mestrado em Educação). Universidade Federal do Rio Grande do Norte. Natal-RN. 2008.

SILVA, R. H. R.; GAMBOA, S. S. Análise epistemológica da pesquisa em educação especial: a construção de um instrumental de análise. Atos de Pesquisa em educação, v.6, n.2, p.373402, mai.-ago. 2011.

VENTORINI, S. E. A experiência como fator determinante na representação espacial do deficiente visual. 2007. Dissertação de Mestrado. Universidade Estadual Paulista. 2007.

VENTORINI, S. E. Representação gráfica e linguagem cartográfica tátil: estudo de casos. 2012. Tese de Doutorado. Universidade Estadual Paulista. 2012. 


\section{Resumo}

\section{Produção do conhecimento sobre o ensino de geografia para pessoas com deficiência}

A matrícula de pessoas com deficiência nas escolas regulares em diferentes etapas tem crescido nos últimos anos e com isso também as pesquisas na interface da educação especial com as outras áreas do conhecimento. O objetivo deste estudo foi analisar a produçáo de pesquisas sobre ensino de geografia para pessoas com deficiência, com foco na visual, bem como analisar os temas pesquisados e as Instituiçóes de Ensino Superior onde as pesquisas se realizaram com vistas a apontar os desafios e as possibilidades para futuros trabalhos. $\mathrm{O}$ referencial teórico sobre análise de produção científica pautou-se em Bueno (2010) e Silva e Gamboa (2011). O levantamento da produçáo foi realizado no banco de teses da Capes, e os descritores utilizados foram: inclusão, deficiência, cegueira e ensino de geografia. Os resultados dessa análise mostram que a escolarização das pessoas com deficiência tem sido um tema em crescimento nas pesquisas dos últimos anos, mas que o enfoque das pesquisas está nas metodologias de ensino. Também há uma indicação para uma possível diversificação nas deficiências estudadas e nas Instituições de Ensino Superior.

Palavras-chave: Ensino de Geografia. Deficiência Visual. Educação Especial.

\section{Abstract \\ Production of Knowledge on the Teaching of Geography for People with Disabilities}

The enrollment of disabled people in regular schools in different stages has been growing in the past years and so has the research on the interface of special education with other fields of knowledge. The goal of this study was to analyze the production of research on geography teaching for disabled people, focusing on visual disability, as well as to analyze the researched topics and universities where they were made, aiming to point out the challenges and possibilities for future research. The theoretical reference on the analysis of the scientific production was based on Bueno (2010) and Silva and Gamboa (2011). The production survey used the bank of thesis of CAPES, with the following describers: inclusion, disability, blindness and geography teaching. The results of this analysis show that the schooling of disabled people has been a growing topic on the research done in the past years, although the focus of research is on teaching methods. There is also an indication for a possible diversification of the studied disabilities and of the universities.

Keywords: Geography Teaching. Visual Disability. Special Education. 